\title{
Entre el Acta de Montevideo y la "transición democrática": actores a favor y en contra de la mediación papal, 1977-1985
}

Cristian Di Renzo*

Fecha de Recepción: 30 de junio de 2021

Fecha de Aceptación: 30 de agosto de 2021

DOI: https://doi.org/10.46553/RGES.57.2021.p.185-206

Resumen: En este artículo, nos proponemos analizar las diferentes percepciones existentes en torno al proceso de mediación papal en torno al conflicto Beagle entre Argentina y Chile. Al respecto consideramos que tanto el escenario interno argentino como el accionar por parte de actores internacionales, volcaron la balanza a favor de la salida pacífica de la crisis en detrimento de aquellos que buscaban otra forma de solución. Dentro de estos últimos, podemos identificar a un sector compuesto por intelectuales, civiles y militares, que no se encontraban de acuerdo con las políticas estatales emprendidas o bien con las decisiones a las que se estaban arribando dentro el proceso de mediación. Tal sería el caso de dos profesionales del Estado e intelectuales militares sobre los que trabajaremos: Osiris Villegas y Ricardo Etcheverry Boneo.

Palabras clave: Intelectualidad militar; Profesional del Estado; Toma de decisiones; Mediación Papal

\begin{abstract}
In this article, we propose to analyze the different perceptions that exist around the papal mediation process around the Beagle conflict between Argentina and Chile. In this regard, we consider that both the Argentine domestic scene and the actions by international actors, turned the balance in favor of a peaceful solution to the crisis to the detriment of those who were looking for another form of solution. Within the latter, we can identify a sector made up of intellectuals, civilians and the military, who did not agree with the state policies undertaken or with the decisions that were being reached within the mediation process. Such would be the case of two state professionals and military intellectuals on whom we will work: Osiris Villegas and Ricardo Etcheverry Boneo.
\end{abstract}

Keywords: Military Intellectuality; Professional of the State; Decision-making; Papal Mediation

\section{A modo de introducción}

La consideración de los militares como intelectuales ha generado críticas y hasta incluso reticencias dentro de la historiografía de las ciencias sociales. ${ }^{1}$ Sin embargo, en esta

\footnotetext{
*Instituto de Humanidades y Ciencias Sociales, Consejo Nacional de Investigaciones Científicas y TécnicasUniversidad Nacional de Mar del Plata. Grupo de Estudios Históricos sobre la Guerra - Instituto Ravignani unidad ejecutora CONICET/UBA, cristiandirenzo1@gmail.com.

${ }^{1}$ El presente artículo forma parte de las investigaciones realizadas en el marco de una Tesis Doctoral en Historia (de pronta defensa), dirigida por el Dr. Germán Soprano y codirigida por el Dr. Julio Melón. La misma, lleva por
} 
investigación, coincidimos en que la caracterización de los militares como depositarios de la última ratio del ejercicio de la violencia (letal), no supone la imposibilidad de comprender algunos perfiles y trayectorias de oficiales como intelectuales del Estado. ${ }^{2}$ Es por ello que en este artículo nuestro objetivo se centra en el análisis de dos figuras que, además de ser profesionales del Estado (por su condición de ser militares de carrera), se desempeñaron en funciones ligadas a la política exterior en los primeros años de la última dictadura civil-militar en Argentina y durante el denominado proceso de "transición democrática". 3

En este sentido, nuestro aporte gira en torno al análisis de las concepciones del general Osiris Villegas en torno al proceso de mediación papal en su obra La propuesta pontificia y el espacio nacional comprometido (1982) considerando a ésta como parte constitutiva de su estrategia para generar consensos con su posición. ${ }^{4}$ Resulta de interés el estudio de su pensamiento, puesto que fue uno de los actores militares involucrados en el periodo 1977-

título: De la hipótesis de guerra a la cooperación en Defensa: actores, estrategias y políticas en las relaciones entre Argentina y Chile entre las décadas de 1970-1990.

${ }^{2}$ Rodríguez, Laura y Soprano, Germán (editores), Profesionales e intelectuales de Estado. Análisis de perfiles y trayectorias en la salud pública, la educación y las fuerzas armadas (Rosario: Prohistoria Ediciones, 2018), p.10.

${ }^{3}$ También situamos esta investigación con aquellos trabajos en los que se destaca la figura del intelectual en los escenarios latinoamericanos, buscando complejizar la relación entre intelectuales, cultura y política. Por citar algunos, Devés Valdés, Eduardo, El pensamiento latinoamericano en el siglo XX: desde la CEPAL neoliberalismo (1950-1990) (Buenos Aires: Biblos, 2000); Altamirano, Carlos (director), Historia de los intelectuales en América Latina (Buenos Aires: Katz editores, 2008); Neiburg, Federico y Plotkin, Mariano, Intelectuales y expertos (Buenos Aires: Paidós, 2004); Di Pasquale, Mariano y Summo, Marcelo, Trayectorias singulares, voces plurales. Intelectuales en la Argentina, siglos XIX y XX (Buenos Aires: EDUNTREF, 2015); otros. Por otra parte, no desconocemos los debates existentes en torno al concepto de "transición democrática" en Argentina, sino que optamos por su utilización de acuerdo a lo sostenido por Feld, Claudia y Franco, Marina (Editoras), Democracia, hora cero. Actores, políticas y debates en los inicios de la posdictadura (Buenos Aires: Fondo de Cultura Económica, 2015).

${ }^{4}$ Para el análisis de las fuentes escritas en la búsqueda de aquellos conceptos que constituyen el objeto de esta investigación, se seguirán las herramientas teóricas provenientes del campo de la Historia Intelectual, especialmente aquellas en las que se prioriza las formas en las que los pensamientos se insertan y se reproducen en un determinado tiempo y espacio Di Pasquale, Mariano, "De la historia de las ideas a la nueva historia intelectual: Retrospectivas y perspectivas. Un mapeo de la cuestión". Universum (Talca), 26(1), (2011): 79 -92 .Preferimos la utilización de la denominación "concepciones" ya que, de acuerdo con lo sostenido por Koselleck, una palabra se convierte en un concepto si la totalidad de un contexto de experiencia y significado sociopolítico, en el que se usa y para el que se usa esa palabra, pasa a formar parte globalmente de esa única palabra", Koselleck, Reinhart, Futuro pasado. Para una semántica de los tiempos históricos (Barcelona: Paidós, 1993), p.117.

A su vez, un concepto articula redes semánticas, lo que le confiere, a su vez, un carácter inevitablemente polivalente. Esa polivalencia conceptual en el nivel sincrónico tiene, pues, fundamentos diacrónicos (ella es un emergente de la malla de significados tejida a lo largo de su misma historia), indicando una inevitable asincronía semántica. En definitiva, en un concepto se encuentran siempre sedimentados sentidos correspondientes a épocas y circunstancias de enunciación diversas, los que se ponen en juego en cada uno de sus usos efectivos (esto es, vuelve sincrónico lo diacrónico). De allí deriva la característica fundamental que distingue a un concepto: lo que lo define es, precisamente, su capacidad de trascender su contexto originario y proyectarse en el tiempo, Palti, Elías, "La nueva historia intelectual y sus repercusiones en América Latina". Revista de Historia Unisinos, septdic. (2007), p. 300. Estas consideraciones metodológicas, lejos de solucionar un problema de mayor magnitud y que comprende los distintos debates existentes dentro de las corrientes que analizan la historia intelectual, no tiene otra función más que dejar en claro cuál es la perspectiva en la cual se observarán las obras de los autores seleccionados. 
1979, formando parte de las misiones diplomáticas, y siendo además uno de los intelectuales militares más destacados entre las décadas de 1960, 1970 y 1980. Del mismo modo, utilizaremos otra fuente: Canal de Beagle. Crónica de una Mediación (2000) obra póstuma, perteneciente a uno de los actores militares involucrados en las negociaciones iniciadas tras la firma del Acta de Montevideo (8 de enero de 1979): el general de brigada Ricardo Etcheverry Boneo. Su abordaje resulta de interés ya que se desempeñó como titular de la delegación argentina ante la Santa Sede, cargo en el que fuera ratificado con la asunción de Raúl Alfonsín. Sin embargo, en 1983 dejó el cargo, aunque continuó presente como asesor de la Misión Especial en Roma, marcando diferencias con la gestión radical sobre el conflicto.

Al respecto, sostendremos la hipótesis de que ambos militares de carrera forman parte de la corriente nacional territorialista irredentista, compartiendo concepciones geopolíticas similares, sobre todo en torno a la imagen negativa que se tiene sobre la República de Chile. ${ }^{5}$ Asimismo, y de acuerdo con estas afirmaciones consideramos que tales concepciones, no encuentran eco dentro del particular clima emocional nacional argentino de la posguerra de Malvinas. ${ }^{6}$ Pues, entre otras características, tal clima distaba de ser confrontativo (menos aún belicista), y el fantasma de una eventual guerra vecinal, fomentada por algunos sectores que apoyaron la aceptación de la propuesta de solución, terminó por aunar voluntades sobre tal ofrecimiento. $^{7}$

Para dar cuenta de estos aspectos, en primer lugar, realizaremos una breve descripción del conflicto Beagle identificando los principales hitos en torno a este. Luego, avanzaremos sobre el análisis del proceso que derivó en la aceptación de la mediación papal, identificando a aquellos actores que apoyaban la iniciativa y a quienes se oponían. Finalmente examinaremos las producciones intelectuales de Osiris Villegas y de Ricardo Etcheverry

\footnotetext{
${ }^{5}$ Di Renzo, Cristian, Entre la diplomacia parcial y la guerra total: concepciones geopolíticas de militares argentinos en el marco del conflicto por el canal de Beagle y las islas Picton, Lennox y Nueva (1977-1979) (Tesis de Maestría en Historia por la UNMDP, 2018).

${ }^{6}$ El empleo del concepto de clima emocional que aquí empleamos, es una interpretación realizada sobre la obra de Casquete, Jesús. Nazis a pie de calle. Una historia de las SA en la República de Weimar (Madrid: Alianza, 2017). Por otra parte, planteamos diálogo con otros trabajos, tales como Bartolucci, Mónica. "La emoción místico patriótica de derechas e izquierdas revolucionarias". Anuario del Instituto de Historia Argentina, 20(1), 2020; y con Di Renzo, Cristian, "El nacionalismo en primer plano: el Operativo Soberanía a través de las fotografías y los relatos de los soldados conscriptos (1978-1979). En Bartolucci, Mónica y Favero, Bettina (compiladoras), En el nombre de la patria. Juventud, nacionalismos cotidianos y emociones patrióticas (Argentina, 1955-1979) (Ciudad Autónoma de Buenos Aires: Teseo, 2021). En ambos trabajos se abordan las características generales del clima emocional nacional en la década de 1970.

${ }^{7}$ Los investigadores Bohoslavsky y Soprano, sugieren una serie de enfoques en los que podemos hallar coincidencias con nuestra investigación (encontrándose en una intersección entre varias de las vertientes señaladas). Al respecto, véase Bohoslavsky, Ernesto y Soprano, Germán, Un Estado con rostro humano. Funcionarios e instituciones estatales en Argentina (desde 1880 hasta la actualidad) (Buenos Aires: Prometeo/UNGS, 2010). En este sentido, en este artículo postularemos que existe una relación entre el proceso de toma de decisiones y la influencia de las producciones intelectuales sobre los diferentes agentes estatales.
} 
Boneo explicando algunos de los motivos por los que sus concepciones no hallaron eco dentro del clima emocional nacional de la posguerra de Malvinas.

\section{Origen y desarrollo del conflicto Beagle. Contexto previo al proceso de mediación papal}

Argentina y Chile comparten una de las fronteras terrestres más extensas del mundo y la labor de definir sus límites no ha sido un proceso exento de conflictos. A lo largo del siglo XIX y en sintonía con las naciones latinoamericanas, se fueron desarrollando diferentes estrategias tendientes a la consolidación de sus fronteras, tanto internas como externas. ${ }^{8}$ Más precisamente, en las últimas décadas del siglo XIX y las primeras del siglo XX las negociaciones binacionales fueron intensas e incluyeron demostraciones de fuerza y de desconfianza que podrían haber desembocado en una guerra vecinal, o incluso regional. ${ }^{9} \mathrm{En}$ este proceso de delimitación fronteriza, se destaca el Tratado limítrofe de 1881 que, al momento de su redacción, había dejado algunas imprecisiones que intentaron ser resultas con el Protocolo Aclaratorio de 1893. Es en este marco en el que tiene origen el conflicto limítrofe por la soberanía del canal interoceánico de Beagle y las islas Picton, Lennox y Nueva, puesto que ninguno de estos dos instrumentos legales fijaron los límites definitivos sobre esta zona.

Además, en estos años, tienen comienzo una serie de percepciones negativas sobre las naciones vecinas de Brasil y Chile, que luego serán retomadas a lo largo del siglo XX por un grupo de intelectuales, civiles y militares que tenían como una de sus premisas centrales la de convertir a la Argentina en potencia( inevitable destino de grandeza). ${ }^{10}$ Para el caso que nos atañe, esta corriente que hemos denominado como nacional territorialista irredentista, nutrió sus diferentes producciones intelectuales de estas interpretaciones y también de los diferentes intervalos conflictivos en las relaciones entre Argentina y Chile a lo largo del siglo XX. ${ }^{11}$

\footnotetext{
8 Botana, Natalio, El orden conservador. La política argentina entre 1880 y 1916 (Buenos Aires: Hyspamerica, 1977); Salazar, Gabriel y Pinto, Julio, Historia Contemporánea de Chile. Volúmenes I al V (Santiago de Chile: Lom Ediciones, 1999-2000); Bohoslavsky, Ernesto y Godoy Orellana, Milton (Editores), Construcción estatal, orden oligárquico y respuestas sociales. Argentina y Chile 1840-1930 (Buenos Aires y Los Polvorines: Prometeo Libros-Universidad Nacional de General Sarmiento, 2010); otros.

${ }^{9} \mathrm{Al}$ respecto, véase Lacoste, Pablo, La imagen del otro en las relaciones de la Argentina y Chile: 1534-2000 (Buenos Aires: Fondo de Cultura Económica y Universidad de Santiago de Chile, Buenos Aires, 2003); y Di Renzo, Entre la diplomacia parcial...

${ }^{10}$ Cavaleri, Paulo, La restauración del Virreinato. Orígenes del Nacionalismo territorial argentino (Bernal: Universidad Nacional de Quilmes, 2004); Escudé, Carlos, “Apuntes sobre los orígenes del nacionalismo territorial argentino". Serie Documentos de Trabajo. Universidad del CEMA. Área: ciencia política, No. 388, 2008.

${ }^{11}$ Por ejemplo, el incidente ocurrido en el islote Snipe del año 1958 o la disputa por la zona de Laguna del Desierto que, en año 1965 produce un enfrentamiento entre los carabineros chilenos y gendarmes argentinos. En el mismo, cae herido de muerte el teniente chileno Hernán Merino, existiendo desde ambos lados de la cordillera expresiones anti argentinas y anti chilenas. Este conflicto, va a encontrar su fin en el año 1991 valiéndose a su
} 
Esta corriente, que nuclea a intelectuales civiles y militares, dedica sus producciones intelectuales al abordaje de los conflictos limítrofes entre Argentina y sus países vecinos, pero también sobre el aprovechamiento de los recursos en áreas fronterizas, el desarrollo nacional, entre otros. Debemos destacar que, si bien gran parte de su matriz conceptual surge a finales del siglo XIX con intelectuales tales como Vicente Quesada y Estanislao Zeballos, es en las décadas de 1960, 1970 y 1980 en las cuales encontrarán mayor difusión, justamente, en instancias en las que Argentina mantiene disputas territoriales o por el aprovechamiento de los recursos con Brasil y Chile. ${ }^{12}$

Tal es el caso del conflicto Beagle que, para finales de 1978, encontraba a las fuerzas armadas de ambas naciones a la espera de la orden de dar comienzo con las hostilidades. En este contexto, los esfuerzos por encontrar soluciones en el plano pacífico, parecían lejanos frente a un enfrentamiento armado que aparentaba no tener marcha atrás. ${ }^{13}$

No obstante, existieron una serie de factores que confluyeron para que se destrabe tal situación. Por ejemplo, debemos hacer mención a los esfuerzos realizados por actores tales como el presidente de facto Jorge Rafael Videla y de sus allegados dentro de una particular división tripartita del poder de la dictadura civil-militar del Proceso de Reorganización Nacional. ${ }^{14} \mathrm{Al}$ no haber una estructura de poder centralizada, existían posibilidades de que

vez, en el Tratado de Paz y Amistad firmado en el año 1985. Al respecto véase Passarelli, Bruno, El delirio armado. Argentina-Chile. La guerra que evitó el Papa (Buenos Aires: Sudamericana, 1998); y Lanús, Juan Archibaldo, De Chapultepec al Beagle. Política exterior argentina: 1945-1980 (Buenos Aires: Emecé, 2000).

Sobre la corriente nacional territorialista irredentista, puede verse Di Renzo, Cristian, "Concepciones geopolíticas en torno a la política regional de Argentina: la Revista Argentina de Relaciones Internacionales (1975-1983)". Coordenadas, (8)1, (2021): 67-88.

${ }^{12}$ Debemos comprender este conflicto regional, dentro de un contexto más amplio en donde el mundo se va alejando, paulatinamente, del esquema bipolar de la guerra fría para dar lugar a uno más cercano a la multipolaridad. Un esquema de análisis en esta clave analítica puede verse en Keohane, Robert y Nye, Joseph, Poder e interdependencia. La política mundial en transición (Buenos Aires: GEL, 1988). Acerca del contexto general de la Guerra Fría, véase Hobsbawm, Eric, El Siglo XX (Barcelona, Crítica, 1998); McMahon, Robert. La guerra fría. Una breve introducción (Madrid: Alianza, 2009).

${ }^{13}$ Pues, la guerra tenía fecha y hora exacta de comienzo: la Argentina cruzaría la frontera para ocupar las islas Picton, Lennox y Nueva viernes 22 de diciembre de 1978 a las 22 hs. Áreas, Tabaré y Palazzo, Sergio, "Cómo se paró la guerra con Chile". Revista Somos, (8 de julio de 1983): 39-44. Hemeroteca del Congreso de la Nación Argentina.

${ }^{14} \mathrm{Al}$ pretender representar una experiencia refundacional, la dictadura civil-militar del Proceso llevó a cabo una serie de estrategias tendientes a evitar, en primera instancia, la concentración del poder, y más precisamente la "personalización" a través de la división tripartita del poder, con una supremacía de la Junta Militar, tal como es señalado en Los Documentos Básicos. Pues la gestión del general Onganía (1966-1969) había dejado como legado a los militares argentinos cuán corrosiva podía resultar la supremacía presidencial por sobre la Junta Militar, a través de la cual las Fuerzas Armadas controlaban la experiencia autoritaria, Canelo, Paula, "Los efectos del poder tripartito. La balcanización del gabinete nacional durante la última dictadura militar". Prohistoria, núm. 17, año XV, (2012): 129-150.

Por otra parte, el empleo del concepto de "dictadura civil-militar" en este artículo se halla justificado, en primer lugar, por la participación política civil en el gobierno de facto del Proceso de Reorganización Nacional y, en segundo lugar, por el hecho de que los militares como profesionales de Estado debido a sus funciones específicas, no son civiles, pero sí ciudadanos. 
existieran diferentes interlocutores en el proceso de toma de decisiones. Por ejemplo, la Cancillería constituía un espacio en el que confluían diversas demandas o aspiraciones de varios integrantes de las Fuerzas Armadas (en actividad o retirados). Es por ello que al momento al que se dio a conocer el dictamen de la Corte Arbitral (Laudo Arbitral del 2 de mayo de 1977), no existieron homogeneidades dentro de los representantes del gobierno de facto. $^{15}$

De esta manera, y ante la heterogeneidad dentro de la cúpula militar, existieron actores con diferentes posiciones en torno al Laudo, que pueden interpretarse como "dura, intermedia y benévola". ${ }^{16}$ La primera posición sostenía que se debía rechazar el Laudo y estaba representada por una parte del Ejército y la Armada. Una segunda posición sostenía rechazar los “considerandos" y aceptar la "parte dispositiva", esgrimida por parte de la Cancillería. Por último, existía un sector ligado a la Consejería Legal y parte de la Fuerza Aérea que consideraba la aceptación del mismo. Como hemos señalado, la división tripartita del poder y la existencia de diversas posiciones, que contaban con sus propias razones y mecanismos para impedir los objetivos de las otras posiciones o favorecer sus posturas por sobre las otras, influyeron sobre los procesos de negociación diplomática. Esto produjo que se elaboren y se refuercen teorías que justificaran sus posiciones.

En este sentido, consideramos que la producción intelectual, académica y militar sobre la temática tuvo un rol central en la construcción/consolidación del conflicto, puesto que las tesis y los conceptos asociados a ellas fueron utilizados como fundamento en el accionar de los distintos actores sociales involucrados, especialmente por aquellos que apostaban por la salida armada en el periodo 1977-1979. ${ }^{17}$ Dentro de este grupo se encontraba, precisamente, el general Osiris Villegas. ${ }^{18} \mathrm{Al}$ respecto, debemos señalar que entre mediados de 1976 y fines

\footnotetext{
${ }^{15}$ El Laudo fue propiciado tras la suscripción del acuerdo para el arbitraje entre Argentina y Chile (22 de julio de 1971). En el Tratado de Solución de Controversias (1972), el Árbitro Británico acepta designar una Corte Arbitral para determinar el límite en el canal de Beagle y la potestad sobre las islas Picton, Lennox y Nueva e islotes adyacentes. La sentencia tendría el carácter obligatorio e inapelable por cualquiera de los dos países involucrados Sanchís Muñoz, José, Historia Diplomática Argentina (Buenos Aires: Eudeba, 2010), p.452.

${ }^{16}$ Russell Roberto, "El proceso de toma de decisiones en la política exterior argentina 1976-1989". En: Russell Roberto, Política exterior y toma de decisiones en América Latina (Buenos Aires: GEL, 1990):13-60.

${ }^{17}$ Di Renzo, De la diplomacia parcial...

${ }^{18}$ La figura del general Osiris Villegas quedó asociada, dentro de la memoria argentina contemporánea, a la defensa ante el Consejo Supremo de las Fuerzas Armadas del general Luciano Benjamín Menéndez por su actuación durante la Guerra de Malvinas. No obstante, su desempeño en el plano militar, político e intelectual, exige un análisis más detenido que no podemos abarcar en su totalidad por cuestiones de extensión, aunque haremos un breve recorrido de su trayectoria. En principio, debemos considerar que tuvo participación en el golpe de Estado de 1955 que derrocó al presidente Juan Domingo Perón. También fue interventor interino en la provincia de Neuquén entre los meses de abril y junio de 1962. Luego de esta intervención, formó parte del gobierno de José María Guido, desempeñándose como ministro del Interior. Siguiendo con esta cronología, el presidente Arturo Illia lo nombró subjefe del Estado Mayor del Ejército y años más tarde participó del golpe de Estado contra este, que derivó en la instauración de la dictadura civil-militar autodenominada "Revolución
} 
de 1977 se establece un puente aéreo entre Buenos Aires y Santiago, con misiones que muestran dos características: están integradas por militares duros, como el general Osiris Villegas y mantienen dos niveles de intercambio-canales paralelos de vinculación y, también diplomacias paralelas-, uno transitado por los funcionarios de la Cancillería y el otro directamente encomendado por la Junta Militar a los representantes de las respectivas fuerzas. ${ }^{19}$ Dentro de este esquema, la Cancillería (que presentó desde el 24 de marzo de 1976 hasta 1983 seis representantes), estuvo ligada a los intereses de aquella facción a la que respondía. ${ }^{20}$ En ella, además, se evidencia una considerable militarización durante los primeros años de la dictadura, que alcanzó un 66,7\% de los niveles superiores del personal en 1976, un $50 \%$ de ellos en actividad. ${ }^{21}$ Sobre este punto volveremos más adelante.

\section{Entre el Acta de Montevideo y la Propuesta Papal}

La mediación es uno de los tres medios más importantes de arreglo internacional de diferendos (los otros son la investigación y la conciliación) y consiste en la acción de una tercera potencia destinada a obtener un arreglo entre los Estados en litigio. En ella, el Estado mediador interviene en la negociación y propone una solución. Tiene la particularidad de que es de carácter facultativo, nada le obliga a ofrecer su mediación, los Estados en litigio pueden declinar el ofrecimiento de este y a diferencia de lo que ocurre con el arbitraje, no puede ser impuesto. Aun así, en la década de 1980, al igual que en el conflicto Beagle, hay otros ejemplos acerca de la actuación como mediador de una personalidad influyente y no de una potencia. $^{22}$

No obstante, en los procesos en los que interviene un tercero como mediador, pueden

\footnotetext{
Argentina”. En los primeros años de ese gobierno de facto, asumió la dirección del Consejo Nacional de Seguridad (CONASE) y entre los años 1969 y 1973 fue embajador en Brasil .En lo que respecta a su contribución intelectual dentro de las Fuerzas Armadas, sus trabajos se centraron, en primer término, en la teorización sobre la seguridad nacional y el "peligro comunista"; y, en segundo lugar, en cuestiones ligadas a la geopolítica del Cono Sur, y particularmente en la década de 1970, sobre el conflicto Beagle.

19 Bosoer, Fabián, Generales y Embajadores. Una historia de las diplomacias paralelas en la Argentina. (Buenos Aires: Vergara, 2005) p. 328.

20 Estos fueron Antonio Vañek, delegado de la Junta militar (24/03/1976-30/03/1976), César Guzzetti (30/03/1976-23/05/1977), Oscar Antonio Montes (23/05/1977-06/11/1978), Carlos Washington Pastor (06/11/1978-29/03/1981), Oscar Camillón (29/03/1981-11/12/1981), Norberto Couto(interino 11/12/198122/12/1981), Nicanor Costa Méndez( 22/12/1981-30/06/1982) y Juan Ramón Lanari (02/07/1982- 10/12/1983).

${ }^{21}$ Canelo Paula," La militarización del Estado durante la última dictadura militar argentina. Un estudio de los gabinetes del Poder Ejecutivo Nacional entre 1976 y 1983". Historia Crítica, No. 62 • Octubre-diciembre (2015): 57-75.

${ }^{22}$ Semberoiz, Edgardo, Derecho Internacional de la guerra (Buenos Aires: Círculo Militar, 1985) .pp.39.40. Podemos agregar que, para el conflicto entre Israel y los Estado Árabes (1984), fueron el conde de Wisborg Bernadotte y el politólogo y diplomático estadounidense ganador del premio Nobel de la Paz Ralph Bunche quienes actuaron como mediadores.
} 
verse dificultados por la existencia de imágenes o representaciones negativas entre las naciones que presentan diferencias en torno a un determinado conflicto. Para el caso que no compete, dentro del esquema tripartito del poder en la dictadura civil-militar del Proceso, las concepciones geopolíticas de la corriente nacional territorialista irredentista generaron consensos dentro del ala más dura en torno a las negociaciones. ${ }^{23}$ La imagen sobre la República de Chile era esencialmente negativa y la misma remitía, sobre todo, a la política fronteriza emprendida desde sus orígenes como nación. Un representante de estos planteos es el general de brigada del Ejército argentino y funcionario estatal, Ricardo Etcheverry Boneo. ${ }^{24}$ Bajo sus concepciones, la política exterior de Chile presenta claros signos de expansionismo. A decir del autor:

"Su objetivo permanente ha sido avanzar hacia el este impulsado históricamente por O’Higgins y los sucesivos gobiernos chilenos. Así fundaron Punta Arenas en 1843, confirmando su derecho al Estrecho de Magallanes y produjeron actos posesorios en las islas, hechos que no motivaron la protesta Argentina o llegó tarde. (...)Siempre tuvieron como guía un claro e irrenunciable objetivo, el dominio del Océano Atlántico al sur de Tierra del Fuego (...) Podrán variar los matices, pero la conciencia territorial es una e indivisible y la política exterior que se encare contará siempre con el apoyo irrestricto del pueblo chileno". 25

Como podemos evidenciar, se sostiene que la política exterior chilena es expansionista en detrimento de la Argentina, cuyos representantes no estuvieron pendientes de esta situación. ${ }^{26}$ Este aspecto encuentra su contraparte en el país trasandino a quien se le asigna

\footnotetext{
${ }^{23}$ Di Renzo, Entre la Diplomacia...

${ }^{24}$ Ricardo Etcheverry Boneo nació en Córdoba el 17 de octubre de 1923 y falleció el 2 de junio de 2002. Ingresó en el Colegio Militar en el año 1941, egresando tres años más tarde con el rango de subteniente del arma de Caballería. Diez años más tarde fue destituido tras ser identificado como uno de los militares que tuvo participación en el movimiento militar contra el presidente Juan Domingo Perón. Posteriormente fue reincorporado a la fuerza y en 1962 comandó el Regimiento V de Caballería y luego quedó a cargo de la Escuela de Caballería. En 1970, ascendió a general de brigada, pasando a retiro al año siguiente. En cuanto a las funciones desempeñadas durante la última dictadura civil-militar, Etcheverry Boneo fue enviado como representante ante la Junta Interamericana de Defensa y luego, formó parte de la Comisión Mixta 2, actuando como embajador junto a su par chileno Francisco Orrego Vicuña. Con la renuncia del embajador Carlos Ortiz de Rozas, en marzo de 1983, se convirtió en el titular de la delegación argentina ante la Santa Sede, cargo en el que fuera ratificado con la asunción de Alfonsín. Sin embargo, posteriormente dejó el cargo, aunque continuó como asesor de la Misión Especial en Roma, encabezada por Marcelo Delpech y Eduardo Candioti como delegado alterno. Completaban el equipo los ministros Susana Ruíz Cerruti y Luis María Ricchieri y el capitán de fragata Osvaldo Astiz.

${ }^{25}$ Etcheverry Boneo, Ricardo, Canal de Beagle. Crónica de una Mediación (Buenos Aires: Círculo Militar, 2000), p.169

${ }^{26}$ En otros pasajes de su obra, sostiene que la política exterior argentina muchas veces estuvo caracterizada, a lo largo de los años, por una conjunción de "grandilocuencia con la ingenuidad", Etcheverry Boneo, Canal de Beagle..., p.188.
} 
una coherencia y constancia por parte de su política de fronteras que, a su vez, es apoyada por el pueblo. No sería el caso de la sociedad argentina, puesto que la misma carecería de conciencia territorial. ${ }^{27}$ Todos estos elementos, con cierta tendencia a ser escritos en modo de denuncia, tienen como finalidad la de generar consensos en torno a una determina posición. En este caso, la de fortalecer los postulados del irredentismo en cuestiones de conflictos limítrofes, en donde ceder una porción de tierra, mar o aire, equivale a la amputación de un miembro del cuerpo. Esto arroja, necesariamente, una imagen negativa de la nación vecina, que además actuaría de similar forma con Perú y Bolivia. ${ }^{28}$

Sin embargo, con esto no se quiere decir que Etcheverry Boneo se encontraba en contra de la mediación o que sea un representante del belicismo, sino que sus concepciones arrojaban una imagen negativa sobre Chile que, en ocasiones, eran tomadas como fundamento para desestimar la opción por un tercero que intervenga. De hecho, fue uno de los actores estatales/militares involucrados tanto en la etapa dictatorial formando parte de la Comisión Mixta 2 (“Comix 2"), como en las negociaciones encaradas por el gobierno de Raúl Alfonsín, aunque con una menor responsabilidad. ${ }^{29}$

Tal como hemos mencionado, la mediación fue propiciada por un conjunto de factores que hacia finales del año 1978 se conjugaron a favor de las posturas anti belicistas. En primer lugar, por Jorge Rafael Videla quien recurrió a la amenaza de la renuncia a la presidencia, evidenciado tras la llegada del ofrecimiento de mediación papal el día 21 de diciembre de $1978{ }^{30}$ Esto fue posible debido a la naturaleza del régimen y al sistema tripartito del poder que trajo consigo, pujas inter e intrafuerzas en los distintos ámbitos en los que se puede manifestar y exteriorizar el poder. Es decir que, debido a que cada fuerza contaba con mecanismos propios para vetar o impulsar ciertas medidas era imposible, al menos para este momento, que existiese la posibilidad de generar una postura hegemónica que logre

\footnotetext{
${ }^{27}$ En este punto existen coincidencias con lo expresado por Villegas en la obra que analizaremos más adelante. Básicamente se señala un debilitamiento de la conciencia nacional debido a las falencias del sistema educativo.

${ }^{28}$ De acuerdo a lo sostenido por Etcheverry Boneo, la estrategia de la expansión territorial chile consistía en "Avanzar exigencias insostenibles, para luego aparecer concediendo sobre lo ajeno al precio de un logro parcial. El elemento primordial de esa política consistía en adquirir precarias posesiones de hecho, para consolidarlas con el transcurso del tiempo. Luego vendría la negociación o arbitraje, siempre sobre territorio argentino", Etcheverry Boneo, Canal de Beagle..., p.76.

${ }^{29}$ Dentro de los esfuerzos realizados por el presidente de facto Jorge Videla, se encontraban las denominadas "Comix". Diferentes comisiones mixtas, "Comix ", debían funcionar en plazos establecidos para tratar de encontrar una solución. Sin embargo, hacia la fecha límite estipulado para concretar un acuerdo, esta es el 2 de noviembre de 1978, no se produjo tal situación, favoreciendo la postura de los duros en las Fuerzas Armadas (segunda posición de cara al conflicto).

${ }^{30}$ De hecho, tras una reunión con el presidente de facto argentino, el embajador norteamericano en Buenos Aires, Robert Hill, sostuvo que “(...) Me fui con la impresión de que Videla no está a cargo, que él no es el jefe y sabe que no lo es (...)". Documento desclasificado del Departamento de Estado, 06276, 24/9/1976 en Bosoer, Generales y Embajadores..., pp.452-455. Si bien el documento está relacionado con los crímenes de lesa humanidad, la opinión resaltada sirve para comprender su situación.
} 
imponerse por sobre los demás fragmentos del poder. ${ }^{31}$

Sumado a esto, con la amenaza de la renuncia por parte de Videla, el general Roberto Viola, próximo sucesor en la presidencia, termina acoplándose a la aceptación de la mediación, la cual fue acatada inmediatamente por Chile, pero no por la Argentina. ${ }^{32}$ En segundo lugar, la operación de ocupación de las islas (planificada para el 22 de diciembre) se vio dificultada debido a la pésima situación climática que se vivía en el extremo austral, lo que retrasó el inicio fehaciente de la lucha directa en vísperas de la hora cero. Tal como señalaba el canciller Washington Pastor: "Por un milagro, debido al mal tiempo en las áreas marítimas australes (...) se logra detener las acciones". ${ }^{33}$ En tercer lugar, el nuevo reparto de los ministerios y áreas de influencia de mediados de 1978 beneficiaron a Videla y a la facción que lo apoyaba, ya que en octubre de 1978 asume a la Cancillería el brigadier Washington Pastor, cuñado del presidente, en detrimento de la renuncia de Oscar Montes, quien en su último tramo de labor había manifestado una postura belicista. En cuarto lugar, podemos nombrar los esfuerzos realizados por la Comisión Mixta 2, encabezada, justamente, por el general de Brigada Etcheverry Boneo. En su obra, sostiene que las sucesivas reuniones y los acuerdos a los que se procuraba llegar eran sistemáticamente desestimados por la intransigencia chilena. No obstante, hacia el final de las reuniones señala que los delegados chilenos le expresaron a su gobierno que "la ayuda de un tercero podría significar el factor determinante". ${ }^{34}$ Por ende, la idea de la mediación era una opción que se barajaba dentro de las negociaciones entabladas por los representantes del Estado Argentino siendo, entonces, otro factor que posibilitó la salida pacífica del conflicto.

Finalmente, en quito lugar, podemos nombrar los esfuerzos realizados por la vía

\footnotetext{
${ }^{31}$ Dentro de este esquema, se debe destacar la misión secreta integrada por diplomáticos de carrera enviados por Videla y por el brigadier Pastor con destinos claves. Así, Susana Cerruti viaja a la Santa Sede y Guillermo Moncayo y Federico Mirré a Washington, Nueva York y Moscú. En Estados Unidos, la reunión decisiva tuvo lugar en la Casa Blanca con Bob Pastor, asesor para asuntos interamericanos del presidente Carter. Se sabe que el representante de Estados Unidos ante la Santa Sede, embajador White, recibió en diciembre de 1978 urgentes instrucciones de su gobierno de pedir al Vaticano que tratara de intervenir rápidamente en el conflicto argentinochileno, Lanús, De Chapultepec..., p.528.

${ }^{32}$ La estrategia emprendida por Videla para/con el conflicto puede entenderse, en términos generales, a partir de que comprendía los efectos a largo plazo en caso de desatarse la guerra, más allá del resultado de carácter catastrófico, Novaro, Marcos y Palermo, Vicente, La dictadura militar. Del Golpe de Estado a la restauración democrática (Buenos Aires: Paidós, 2003), pp. 255-256.

${ }^{33}$ Novaro Marcos y Palermo, Vicente, De la dictadura..., p. 255.

En consonancia con estas expresiones, en las entrevistas realizadas por el investigador a ex soldados conscriptos que se encontraban cumpliendo funciones en el extremo sur austral, se hace mención a las inclemencias climáticas del citado día. Acerca del trabajo con entrevistas a ex soldados conscriptos movilizados en el Operativo Soberanía, véase Di Renzo, Cristian y Mosiewicki, Francisco, "Jóvenes conscriptos argentinos en tres espacios de movilización militar, década de los años setenta". Historia y MEMORIA, n 18, (2019): 149-175; y Di Renzo, Cristian, "El nacionalismo en primer plano ...”.

${ }^{34}$ Etcheverry Boneo, Canal de Beagle..., p. 67.
} 
diplomática del gobierno norteamericano a través del embajador Raúl Castro y por parte de la Iglesia Católica. En particular, los esfuerzos realizados por Monseñor Pío Laghi y por el Cardenal Antonio Samoré, entre otros actores eclesiásticos, fueron importantes en pos de encontrar una salida pacífica al conflicto para lo cual recurrieron a diversos mecanismos. ${ }^{35} \mathrm{En}$ este orden, las acciones de la iglesia católica fueron apoyadas por los Estados Unidos de manera activa y decidida. Por ejemplo, el embajador Raúl Castro, desplegó una intensa actividad a favor de la mediación. En varias oportunidades conversó con Videla, concurrió al Comando en Jefe del Ejército, visitó el Primer y Tercer cuerpo del Ejército y se entrevistó en repetidas ocasiones con autoridades de la Iglesia Católica argentina y con el Nuncio Apostólico, Pío Laghi. ${ }^{36}$ Al respecto, hay investigadores que sostienen que el margen de negociación en esta etapa no solo se vio limitado por diversos factores internos, en especial en el caso argentino, sino también por la forma en que la política de derechos humanos de Estados Unidos condicionó la dimensión bilateral. ${ }^{37}$ En consonancia con esta hipótesis, consideramos que este factor, la denuncia y condena pública hacia ambos países por los delitos contra los Derechos Humanos, hizo que se apostara aún más hacia la mediación del Vaticano que a una intervención directa por parte del gobierno de los Estados Unidos. ${ }^{38}$

Estos esfuerzos en conjunto, dieron sus frutos y el 21 de diciembre de 1978 monseñor Agostino Casaroli, invita a los embajadores de Argentina y Chile ante la Santa Sede para realizar el ofrecimiento de un representante de alto nivel (el cardenal Antonio Samoré) para intervenir en el conflicto. Al día siguiente, ambos gobiernos manifestaron su apoyo ante tal iniciativa. ${ }^{39}$ El mismo Videla, recordará veinte años después el momento en el que recibió el

\footnotetext{
${ }^{35}$ De hecho, la posibilidad de que existiera un tercero como mediador, ya había sido barajada dentro de una de las misiones paralelas tras el fracaso de la Comix II .Incluso en el mes de octubre de 1978, Videla había sugerido a los cardenales argentinos(invitados al evento por Monseñor Pío Laghi), durante una cena en la Nunciatura Apostólica en Buenos Aires, de realizar un ofrecimiento al Papa para que intervenga como mediador, Giaquinta, Carmelo, El tratado de paz y amistad entre Argentina y Chile (Buenos Aires: Ágape, 2009), p.137. Por otra parte, los pormenores de los esfuerzos realizados por Pío Laghi y por Raúl Castro pueden obtenerse en Passarelli, El delirio armado...

${ }^{36}$ Russell, "El proceso...", p.51.

En términos generales, la trayectoria de la diplomacia vaticana tiene la característica de ser más una facilitadora que un actor de primera línea en las relaciones internacionales. La fuente última del poder y prestigio de la Santa Sede radica principalmente en su misión pastoral. Al respecto véase Fermandois, Joaquín, "El cono sur y los conflictos interestatales: la ruta a 1978". En Camusso, Marcelo y Fonrouge, Luis (Compiladores) Los frutos de la paz: la mediación de Su Santidad Juan Pablo II en el diferendo austral entre Argentina y Chile (Buenos Aires: Educa, 2009).

${ }^{37}$ A respecto, véase Villar, Andrés, "El desconocido papel de los EE.UU. en la Crisis del Canal del Beagle. Estudios Internacionales, Santiago de Chile. Vol.46, nº178, (2014): 35-63.

${ }^{38}$ No obstante, dejamos para futuras investigaciones el análisis de este postulado que lo planteamos más con una interrogación que como una hipótesis acabada.

${ }^{39} \mathrm{Al}$ respecto, Russell señala que la presión moral de la autoridad papal había logrado su efecto y los duros debieron acatar a disgusto una decisión que no compartían, pero a la cual tampoco podían oponerse Russell, "El proceso...”, p. 52 .
} 
cable del Vaticano:

"E1 22 estábamos reunidos con la Junta. Estaban Lambruschini, Viola y Agosti, que había postergado su retiro a raíz de este tema para no irse en medio del problema. Cuando estábamos deliberando, ahí llegó justo un cable del Vaticano que decía: "Su Santidad insta a no innovar a la espera de un enviado". En el cable, el Papa decía que la llegada se produciría el 26. Entonces se inició una discusión muy dura porque no era fácil parar, porque ya se había dado la orden, porque los buques navegaban hacia el objetivo y esperaban la orden de fuego. Yo dije, entonces, ésta es la oportunidad que buscamos, debemos parar y esperar al enviado. La posición más dura era de la Armada. Agosti era más flexible. Para Viola esto era un problema, él era mi sostén, y como comandante él tenía que convencer a los generales. Y no era fácil”. ${ }^{40}$

A partir del análisis de este fragmento de la entrevista realizada por Seoane y Muleiro, podemos tomar nota de algunas cuestiones. En primera instancia, constatamos la posición que tenía el presidente de facto argentino de no optar por la vía armada, pues todos sus esfuerzos se centraban en imponer la mediación como medio idóneo para resolver el conflicto limítrofe. En segundo lugar, resulta interesante problematizar el concepto de obediencia debida, pues, como señala el mismo Videla, la tarea de convencer a los generales que apoyaban la opción bélica, no era una tarea fácil de realizar. Es decir que, en la cadena de mando, existían cuestionamientos y diferencias entre la máxima autoridad dentro de la cadena de mando y sus subordinados. ${ }^{41}$ Finalmente, deja en claro que la posición más dura dentro de las diferentes facciones existentes era la de la Armada, pues en ella, la postura del Almirante Massera era central. $^{42}$

En consecuencia, podemos evidenciar la heterogeneidad existente dentro de la Junta en su conjunto, pues no existían coherencias inter-intra armas en el torno al conflicto ni tampoco la figura de Videla era la que simbolizaba un liderazgo absoluto. Asimismo, podemos sostener que en el periodo 1977-1979, la Cancillería, lejos de actuar como el organismo encargado de las relaciones exteriores de la Nación y su representación ante los gobiernos extranjeros y organismos internacionales quedó, entonces, sujeta a la voluntad, a la

\footnotetext{
${ }^{40}$ Seoane, María y Muleiro, Vicente, El dictador: la historia secreta y pública de Jorge Rafael Videla (Buenos Aires: Sudamericana, 2012), p.391.

${ }^{41}$ Sobre este aspecto dentro del Ejército Argentino, trabajaremos en futuras investigaciones.

${ }^{42}$ Estas expresiones son coincidentes con los planteos que señalan que la mediación era rechazada por los halcones del Ejército y de la Armada tales como Luciano Benjamín Menéndez, Carlos Suárez Mason, José Antonio Vaquero, Osiris Villegas y Eduardo Massera. Favorecían la idea de ocupar las islas como único medio de flexibilizar la posición chilena, sin que esto implicara necesariamente llegar a la guerra, Russell , "El proceso...", p.48.
} 
perspectiva, de quien fuera el máximo representante del arma beneficiada con su asignación temporal.

Incluso, hubo intentos directos para frenar la firma del Acta de Montevideo. El General Luciano Benjamín Menéndez se presentó en aeroparque, el 8 de enero de 1979 en traje de fajina para sugerirle al canciller Washington Pastor, con tono elevado, que no viaje a Montevideo, donde estaba por suscribirse el acuerdo de mediación papal. ${ }^{43}$ Sin embargo, en los primeros días de enero de 1979, el Cardenal Samoré se reunió con varios representantes entre ellos el presidente Videla, los tres comandantes en jefe, cancilleres y representantes de la iglesia en pos de conciliar una postura de cara a la firma del Acta de Montevideo. ${ }^{44}$ El texto es muy claro al respecto:

“4-Que su Santidad el papa Juan Pablo II manifestó el deseo de enviar a las capitales de los dos Estados un representante personal suyo para obtener informaciones más directas y concretas sobre las posiciones respectivas y para contribuir al logro de un arreglo pacífico de la controversia"

8.-“Declaran que ambos gobiernos renuevan en este acto su reconocimiento al Sumo pontífice Juan Pablo II por el envío de un representante especial (...)". ${ }^{45}$ Acerca del compromiso firmado el mismo día del Acta, ambos países acuerdan que: "El cardenal Antonio Samoré, enviado especial de Su Santidad Juan Pablo II, al recibir la solicitud de mediación formulada por los gobiernos de la República Argentina y de la República de Chile, pide dicha solicitud vaya acompañada con el compromiso de que los dos Estados no recurrirán a la fuerza en sus relaciones mutuas, realizaran un retorno gradual a la situación militar existente al principio de 1977 y se abstendrán de adoptar medidas que puedan alterar la armonía en cualquier sector". 46

En suma, en el Acta de Montevideo y en el texto de Compromiso, ambas partes se comprometían a la aceptación de la mediación papal y a no hacer uso de la fuerza o a amenazar por medio de esta para no alterar el equilibrio de la paz. Consideramos que el documento resultante compone un elemento clave para disminuir la tensión bélica y política entre ambas naciones. La firma de estos acuerdos binacionales constituye un ejemplo de cómo el accionar por parte de ciertos actores estatales pueden perjudicar o, en este caso, favorecer

\footnotetext{
${ }^{43}$ Bosoer, Generales y Embajadores..., pp. 330-331.

${ }^{44}$ El Acta de Montevideo, la igual que el Compromiso, fueron firmados por Carlos Washington Pastor, ministro de Relaciones Exteriores y Culto por parte de Argentina y por Hernán Cubillos Sallato, ministro de Relaciones Exteriores, por parte de Chile.

${ }^{45}$ Acta de Montevideo, firmada entre Argentina y Chile el 8 de enero de 1979.

${ }^{46}$ Texto de Compromiso firmado entre Argentina y Chile el 8 de enero de 1979.
} 
una determinada postura dentro de un conflicto en el que no existían homogeneidades sobre cómo proceder. Se iniciaba así, la etapa de mediación operativa que concluye el 12 de diciembre de 1980 con la entrega de la Propuesta de Paz de Juan Pablo II. ${ }^{47}$

A continuación, veremos una graficación de la Propuesta producto de las negociaciones:

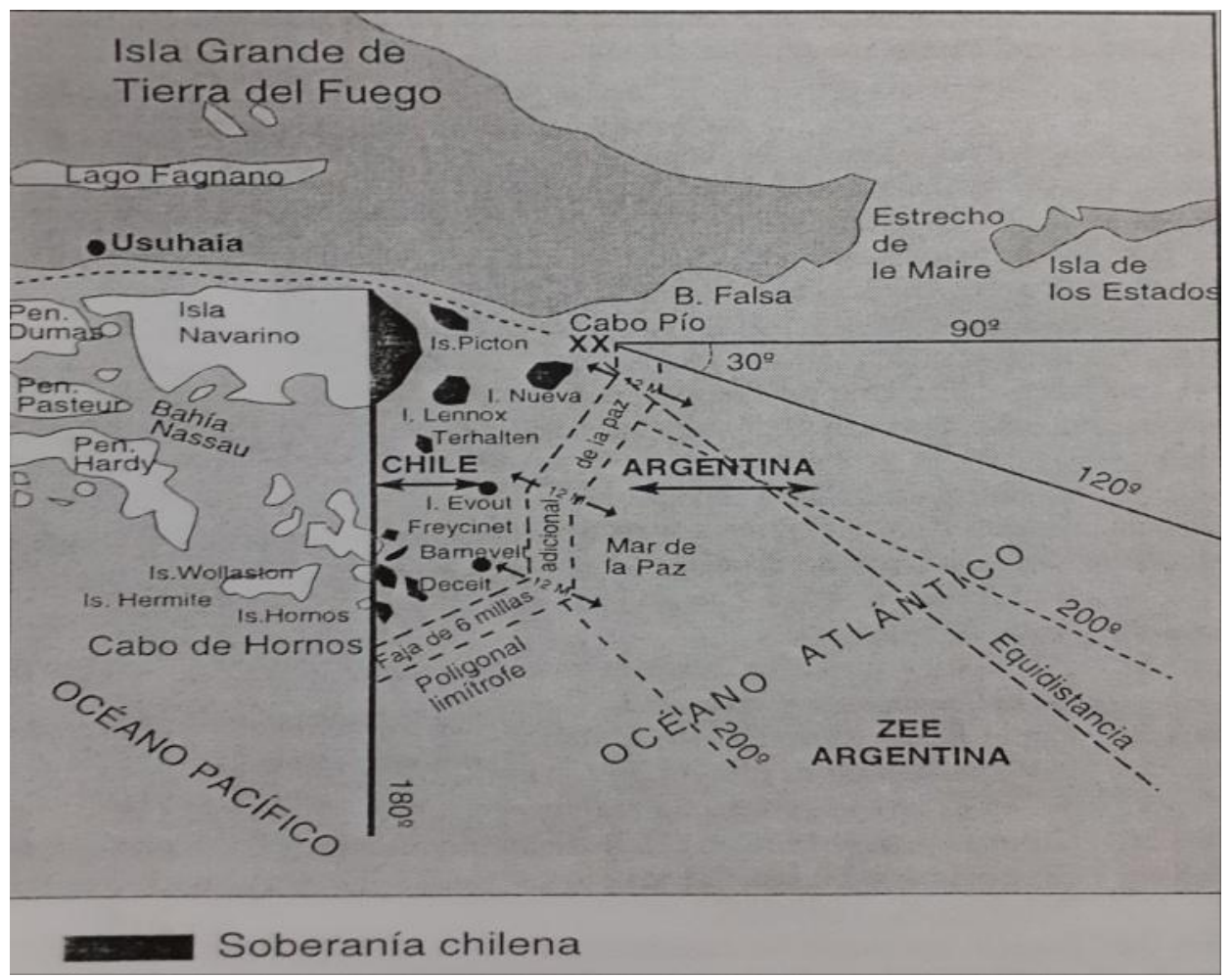

Imagen I-1. Propuesta Papal 1980. ${ }^{48}$

Como podemos observar, se sugiere que todas las islas en disputa junto con el canal Beagle corresponderían a Chile, con lo cual existe una continuidad con lo expresado en el Laudo Arbitral de 1977. Además, se determinó una traza de 12 millas náuticas para la delimitación de las jurisdicciones marítimas utilizando el sistema de las envolventes hasta tocar el meridiano como divisoria oceánica, hasta las 200 millas náuticas. Sin embargo, esta propuesta y la recibida en 1984, despertó la oposición de un grupo de intelectuales militares y civiles que no tardaron en objetar sus postulados.

\footnotetext{
47 Acerca de este proceso, Etcheverry Boneo manifiesta que la Diplomacia chilena se encontraba representada por" profesionales de gran capacidad y cultura, perfectamente ensamblados en cumplir con éxito su plan de trabajo", Etcheverry Boneo, El canal Beagle..., p.178. Estos postulados son coincidentes con los de la corriente nacional territorialista irredentista, ya que una de sus características es realizar comparaciones entre los representantes de la política exterior argentina (desinteresada y poco formada en materia de fronteras nacionales) y los representantes chilenos (profesionales de Estado, con formación acorde a los intereses nacionales).

${ }^{48}$ Extraído de Fraga, Jorge, La Argentina y el Atlántico Sur. Conflictos y objetivos (Buenos Aires: Instituto de Publicaciones Navales, 1983).
} 


\section{Entre la Propuesta Papal y el Tratado de Paz y Amistad}

Podemos anticipar que tanto la propuesta de 1980 como la de 1984 (en la que se destaca la división entre los océanos a través de líneas de bases rectas) no resultaba justa para Etcheverry Boneo, puesto que se le asignaba a Chile el territorio insular controvertido y, además, se consideraba que la denominada zona del "mar de la paz" (presente en la propuesta de 1980), traería aparejado potenciales conflictos futuros. ${ }^{49}$ Similares afirmaciones realizaba uno de los máximos exponentes de la citada corriente, el general Osiris Villegas en la fuente que hemos seleccionado. ${ }^{50}$ De hecho, en la misma portada ya se puede anticipar su postura:

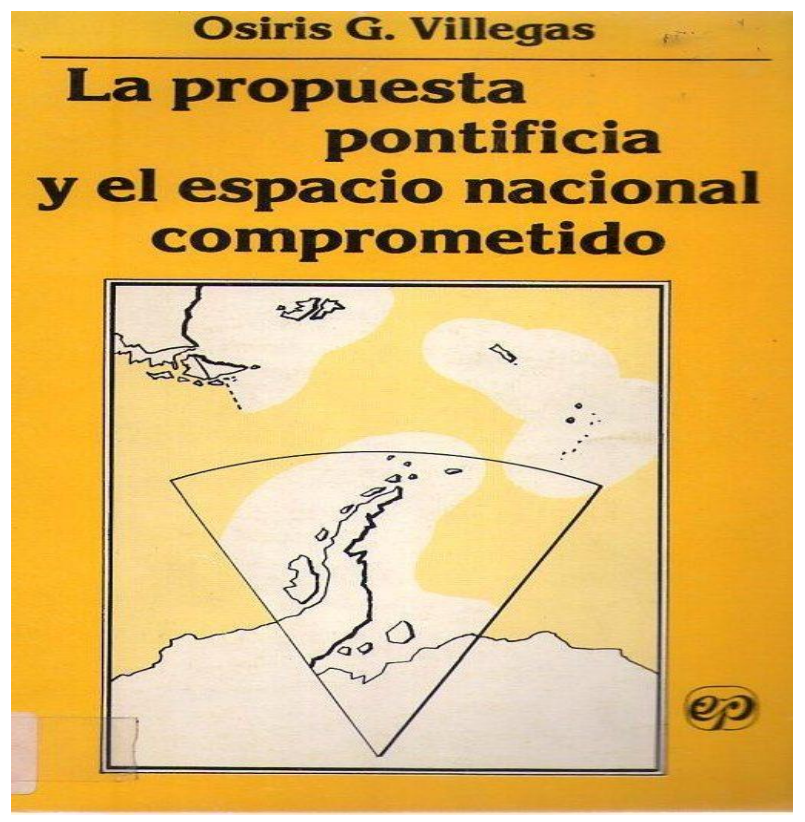

Imagen I-2. Portada de la obra La propuesta pontificia y el espacio nacional comprometido

Esta obra constituye un ejemplo de cómo Villegas procuró influenciar en la acción estatal, luego de que acabara su participación en las misiones diplomáticas, desde su lugar como intelectual militar. Pues, además de este trabajo, redactó contemporáneamente numerosos artículos en revistas específicas de las fuerzas armadas y en otras que exceden al ámbito castrense, tales como Geopolítica y también desplegando sus argumentos en

\footnotetext{
${ }^{49}$ Más allá del desacuerdo con la Propuesta de 1980, Etcheverry Boneo considera que la nueva propuesta del 11 de junio de 1984 "era más desfavorable que la original”, Etcheverry Boneo, Canal de Beagle..., p.172.

${ }^{50} \mathrm{Al}$ respecto, Villegas sostiene que "La propuesta pontificia es preocupante, en vista de la reordenación territorial y marítima que promueve, totalmente distinta al pensamiento político argentino, sostenido desde hace más de un siglo y por ser, además, cantera abierta para conflictos futuros" Villegas, Osiris, La propuesta pontificia y el espacio nacional comprometido (Buenos Aires: PLEAMAR, 1982), p. 56.
} 
numerosos cursos, jornadas y exposiciones temáticas sobre el conflicto Beagle. ${ }^{51}$

Tal como se puede observar, la portada (Imagen I-2) no ilustra la propuesta papal justamente dicha, sino que ejemplifica cuál sería una resolución adecuada para Villegas puesto que las islas en cuestión, y las aguas que las bañan, quedarían bajo la soberanía argentina. En este esquema, la división oceánica (establecida en el Protocolo Aclaratorio de 1893) quedaría resguarda y más importante aún, Chile no tendría acceso al Atlántico salvaguardando el equilibrio geopolítico de Latinoamérica. ${ }^{52}$ Además, se le otorga cierta centralidad al espacio antártico, una de las preocupaciones constantes de Villegas, ya que también actúa como fundamento de su posición de resguardo del "interés nacional". 53

La obra en sí misma, escrita de manera íntegra bajo las concepciones del irredentismo, está redactada con la intensión de generar el interés y el apoyo de la población en un intento de generar consensos mayoritarios de que la propuesta papal sólo beneficia a Chile. Dando claros signos de su contemporaneidad, en la misma introducción se llama a que se genere una "reflexión serena, no influenciada por disposiciones anímicas". ${ }^{54}$ Pues, si bien el inicio de la obra tiene fecha del 27 de abril de 1982, la misma tiene aparición el 3 de agosto del mismo año, con lo cual la derrota en la Guerra de Malvinas ya había tenido lugar. Por ende,

\footnotetext{
${ }^{51}$ En este sentido, consideramos que su accionar no resultó en vano, puesto que los límites de la acción estatal son porosos, siendo estos el resultado de un proceso permanente de desafíos, restauración y relegitimación protagonizado por personas, grupos e instituciones "estatales" y "no estatales", Bohoslavsky, Ernesto y Soprano, Germán. Un Estado con rostro humano. Funcionarios e instituciones estatales en Argentina (desde 1880 hasta la actualidad) (Buenos Aires: Prometeo/UNGS, 2010), p.30.

${ }^{52}$ El equilibrio del poder (balance of power) es un concepto ligado a la Teoría de las Relaciones Internacionales desde sus orígenes. Diferentes escuelas de Relaciones Internacionales lo han adoptado variando su contenido de acuerdo con las necesidades de su modelo de análisis. Desde los clásicos del realismo de post-guerra (Hans J. Morgenthau) hasta los nuevos realistas "de moda" en el momento actual (Kenneth Waltz), pasando por los sistémicos de los años sesenta (Morton Kaplan); todos han recurrido a la noción de equilibrio del poder para elaborar su teoría de las Relaciones Internacionales. También en el terreno práctico -la dirección de la política exterior- se puede hablar de la aplicación del equilibrio del poder. Por ejemplo, la labor de Henry Kissinger al frente de la política exterior de los Estados Unidos ha sido calificada de política de equilibrio del poder entre las superpotencias, Barbé, Esther "El papel del realismo en las relaciones internacionales (La teoría política internacional de Hans J. Morgenthau)". Revista de Estudios Políticos, 1987, no 57, pp.5.

${ }^{53} \mathrm{Su}$ conceptualización acerca de la noción de interés nacional comparte algunos elementos con los postulados de Hans Morgenthau, proveniente de la corriente realista de las relaciones internacionales.

Hans Morgenthau señala, a grandes rasgos, que el interés nacional debe actuar como el elemento fundamente de la política exterior de los Estados. En este sentido, tal noción de encuentra ligada al concepto de supervivencia de cada Estado en un escenario mundial, potencialmente hostil en donde la tarea de preservación de la seguridad le compete directamente al Estado. Di Renzo, Cristian. "De las palabras a las armas: las concepciones geopolíticas de Isaac Rojas y Osiris Villegas entre las décadas de 1960 y 1970". En Arias Neto, José da Silva Rodrigues, Fernando y Soprano, Germán (Coordinadores). Fuerzas Armadas, fronteras y territorios en Sudamérica en el siglo XX: Perspectivas y experiencias desde Argentina y Brasil. La Plata: Universidad Nacional de La Plata. Facultad de Humanidades y Ciencias de la Educación, 2021) p. 318.

Asimismo, en Relaciones Internacionales, el concepto de interés nacional ha permeado gran parte de los estudios, principalmente los posteriores a la Segunda Guerra Mundial, y constituyó uno de los principales elementos del acervo de la corriente teórica realista clásica, Deciancio, Melisa. "La construcción del campo de las Relaciones Internacionales argentinas: contribuciones desde la geopolítica. Revista de Relaciones Internacionales Estrategia y Seguridad, nº12(2017), p. 186.

${ }^{54}$ Villegas, La propuesta ..., p.2.
} 
planteamos que Villegas es consciente que dentro del clima emocional nacional argentino un nuevo enfrentamiento armado no era deseable en gran parte de la población. Esta situación estaría actuando como un factor determinante hacia la aceptación de la propuesta papal, algo con lo que este militar de carrera no estaba de acuerdo. Paz por territorio no era algo negociable para el sector que representa, con lo cual la propuesta era inaceptable. Esta situación, la de recurrir al fantasma de la guerra, fue utilizado luego por parte de un sector del gobierno democrático de Raúl Alfonsín en ocasión del llamado a la Consulta Popular No Vinculante. ${ }^{55}$

Siguiendo con el análisis de la obra de este profesional del Estado, hallamos referencias sobre sus concepciones acerca de Chile, entendiendo a esta como una nación expansionista, con ambiciones geopolíticas de convertirse en potencia bioceánica, y portadora de valores ajenos a la buena fe, asociándola a su vez, con Gran Bretaña. ${ }^{56}$ Esta estrategia, la asociación de un enemigo regional con una potencia mundial colonialista, cobra mayor significado en el contexto en el cual fue escrita la obra dado el sentimiento anti británico expandido dentro de la población en la posguerra de Malvinas. ${ }^{57}$ Bajo estas consideraciones, cualquier alianza entre las naciones vecinas sería inviable, puesto que la desconfianza mutua impide el proceso de entendimiento y más aún el de integración.

Expresando una lectura para nada favorable acerca de la propuesta, considera que la paz a la que se pretende llegar a través de la mediación traería consecuencias graves para la nación. Por ejemplo, y citando lo dicho por el Cardenal Primatesta ("Dios va a darnos la paz, pero con nuestra generosidad y el esfuerzo de todos" y con relación a la propuesta, "hay que leerla con atención y menos pasión"), sostiene que el precio a pagar sería una "mutilación geográfica del territorio argentino". 58 Además, su argumento se profundiza al señalar que: "Hace tiempo que se viene mezclando lo religioso con lo terrenal, la soberanía, con la decisión sobre asuntos de la Nación por estructuras externas o injerencia de gobiernos extranjeros (...)" ${ }^{59}$ A partir de estas ideas, este intelectual militar, denuncia una campaña de acción psicológica por parte de los representantes de la Iglesia Católica por sobre la población, sobre todo, en la juventud. Esto es un elemento relevante puesto que para las clases siguientes de jóvenes que continuaban a las que fueron movilizadas en 1982, una guerra vecinal ya no era una posibilidad remota. Además de la Guerra de Malvinas, ya habían tenido

\footnotetext{
${ }^{55}$ Sobre este punto, trabajamos en la citada Tesis de Doctorado en Historia.

${ }^{56}$ Por ejemplo, véase Villegas, La propuesta..., pp. 2, 52, 67, 81, 88, 100 y101.

${ }^{57}$ Además, se reitera una suerte de revanchismo territorial por parte de Argentina, Perú y Bolivia para/con Chile.

${ }^{58}$ Villegas, La propuesta..., p.87.

${ }^{59}$ Villegas, La propuesta..., p.87.
} 
contacto con los preparativos y la puesta en práctica del Operativo Soberanía unos años antes. $^{60}$

De esta manera, en la obra se señalan las diferentes acciones llevadas a cabo por los cardenales Primatesta y Silva Enríquez, el Obispo de Neuquén, Monseñor de Nevares, por el obispo auxiliar de Buenos Aires, monseñor Calabresi y otros actores religiosos. La misma tendría como fin la implantación de la idea de la paz a cualquier precio. A decir del autor:

"Se fomenta de tal suerte un sentimiento adverso a toda lucha, así sea en defensa de la Patria y la soberanía, con una profundidad que, ni remotamente, había logrado la propaganda de la agitación subversiva ni lo curas tercermundistas.

Las marchas multitudinarias, los enunciados difusos, los cánticos con letras aviesas, los actos de fe y los sermones de los sacerdotes y la propaganda de algunos laicos, persiguen como objetivo crear un cuadro de franca repulsa a todo lo que signifique la obligación constitucional de armarse en defensa de la Nación". 61

Estas duras acusaciones de Villegas lo posicionan como uno de los actores castrenses que mayor aversión manifiesta en torno a la mediación y, sobre todo, al rol de la Iglesia a través de sus representantes. Prácticamente se lo asemeja a las dinámicas emprendidas por parte de la "subversión", lo cual no es un dato menor dada las características que tuvo en Argentina la implementación del Terrorismo de Estado por parte de la última dictadura civilmilitar. Dicho de otra manera, en sus planteos se evidencia que la posibilidad de la guerra como mecanismo para destrabar el conflicto aún era una opción real aun para 1982. En suma, la patria y la soberanía, además de la utilización de conceptos propios de la corriente a la que pertenece tales como el de mutilación, aparecen de manera constante al largo de su obra en la que no existen matices. ${ }^{62}$

De todas formas y de acuerdo a lo solicitado por el Papa, el 8 de enero de 1981 el gobierno de Chile aceptó la propuesta. Entretanto, la respuesta de la Argentina se demoró hasta el 25 de marzo. La solución no era convincente para todos los sectores cercanos a la Junta Militar del Proceso y el año 1981 presentó varios altibajos en las relaciones

\footnotetext{
${ }^{60}$ Esta situación fue más evidente en localidades fronterizas y en distintas ciudades costeras, tales como Bahía Blanca o Mar del Plata, en la que se realizaron ejercicios de oscurecimiento, deportaciones de ciudadanos chilenos y otras actividades impulsadas desde el gobierno civil-militar.

${ }^{61}$ Villegas, La propuesta..., p.92.

${ }^{62}$ Villegas recurre a la historia, como en otros trabajos, para describir el proceso de desarticulación de la nación a favor del modelo agro exportador centrado en la Pampa Húmeda, sumado a una falta de política constante en educación con miras a generar una consciencia territorial en la población.
} 
bilaterales. ${ }^{63}$ De hecho, en abril del mismo año, el comandante en jefe del Ejército argentino, Leopoldo Fortunato Galtieri ordenó el cierre de la frontera. En enero del año siguiente, ya con Galtieri en función de presidente de facto, el gobierno argentino recurre a la denuncia unilateral del Tratado de Solución Judicial de Controversias (que había sido suscrito con Chile en 1972).$^{64}$ Meses más tarde, precisamente en abril de 1982, las operaciones militares argentinas se centraron en la recuperación de las Islas Malvinas y posteriormente, se abocaron a la defensa armada de las mismas. Aun así, el 23 de abril Juan Pablo II realizó una convocatoria a los representantes de ambos países para encontrar una solución definitiva al conflicto.

Al respecto de las negociaciones entabladas durante el año 1982, Etcheverry Boneo sostiene que "Es muy probable que tanto Chile como la Santa Sede pensaran en capitalizar el clima interno desfavorable que se registraba en la República Argentina, con motivo de la Guerra de Malvinas". ${ }^{65}$ En otras palabras, tanto Chile como la Santa Sede habrían intentado usufructuar el clima emocional nacional signado por la derrota en la guerra para favorecer a una solución definitiva. ${ }^{66}$ Mismas afirmaciones fueron realizadas por Villegas. ${ }^{67}$ Es decir que existen coincidencias entre ambos autores acerca de este punto que aparece como una estrategia más de los actores a favor de encontrar una solución definitiva a partir de la mediación. Asimismo, consideramos que los argumentos, y las diferentes estrategias desplegadas por estos actores, exceden a la transmisión y adquisición de saberes teóricos y prácticos específicos dentro de las Fuerzas Armadas, con lo cual se distancian de aquellas labores fundamentales dentro de la formación militar que les son propias. ${ }^{68}$

Finalmente, la derrota en la Guerra de Malvinas y los aprestos para la salida del gobierno por parte de los militares argentinos generó que las negociaciones quedaran pendientes hasta la asunción de la nueva gestión que recurrió, dentro de sus estrategias, al llamado a una Consulta Popular No Vinculante en el año 1984 para convalidar la aceptación

\footnotetext{
${ }^{63}$ Durante esta etapa se generaron diferentes documentos por parte de la delegación argentina para contrarrestar y mejorar los términos de la propuesta.

${ }^{64}$ Este profesional de Estado, se manifiesta a favor de esta decisión ya que consideraba que los resultados de la Argentina en torno a los diferendos limítrofes establecidos bajo las pautas del Tratado de 1972 eran perjudiciales.

${ }^{65}$ Etcheverry Boneo, Canal de Beagle..., pp.143-144.

${ }^{66} \mathrm{Al}$ igual que otros exponentes militares y civiles, se hace mención a la colaboración de Chile con Gran Bretaña durante la Guerra de Malvinas, fortaleciendo así, la imagen negativa del país vecino.

${ }^{67}$ Villegas, La propuesta..., p.3.

${ }^{68}$ Para un abordaje relacionado a estos aspectos, véase Badaró, Máximo, Militares o Ciudadanos. La formación de los oficiales del Ejército Argentino (Buenos Aires: Prometeo, 2009); Frederic, Sabina Et. Al. "La formación militar como formación moral: transmisión y adquisición de saberes teóricos y prácticos en las Fuerzas Armadas". En Frederic, Sabina, Graciano, Osvaldo y Soprano, Germán (coordinadores), El Estado argentino y las profesiones liberales, académicas y armadas (Rosario: Prohistoria Ediciones, 2010); otros.
} 
de la nueva propuesta. ${ }^{69} \mathrm{Al}$ respecto, consideramos que dentro de los lineamientos en Política Exterior del gobierno radical (fuerza triunfante de las elecciones de diciembre de 1983) existe una tendencia hacia la integración en Latinoamérica con base en la solidaridad, la resolución pacífica de los conflictos existentes y la necesaria cooperación entre las naciones que la componen. Si bien estas concepciones no son novedosas, el contexto propio de la "transición democrática", junto con la impronta que dejó la Guerra de Malvinas dentro del clima emocional nacional argentino, favoreció a la diseminación de estas ideas en un proyecto de gobierno que pretendía establecer una ruptura con el pasado inmediato. ${ }^{70}$ Dentro de este nuevo contexto, las concepciones geopolíticas confrontativas del irredentismo no lograron masificarse dentro de la población que apoyó la postura del gobierno democrático en las urnas. $^{71}$

Si bien el tratamiento de este tema amerita un análisis con mayor detenimiento, nos interesa subrayar que para Etcheverry Boneo, el triunfo del Sí en la Consulta Popular No Vinculante, se debió a que "la ciudadanía no recibió de forma adecuada la información requerida o lo que es peor, le fue transmitida en forma distorsionada". ${ }^{72}$ Pues para este actor, la política exterior emprendida por el gobierno de Raúl Alfonsín con relación al conflicto Beagle habría perjudicado los intereses territoriales de los argentinos al presentar una posición

\footnotetext{
${ }^{69}$ Un dato importante es que el 3 de febrero de 1983 falleció el Cardenal Antonio Samoré, siendo reemplazado por Monseñor Gabriel Montalvo. De acuerdo a lo sostenido por Etcheverry Boneo, la personalidad de este representante de nacionalidad colombiana, introdujo un "estilo áspero en las conversaciones”, Etcheverry Boneo, Canal de Beagle..., p.141.

${ }^{70}$ Dentro del campo de las Relaciones Internacionales, existen trabajos sobre la relación entre el cambio de tipo de régimen y la política exterior, entre ellos Hirst, Mónica y Russell, Roberto . "Democracia y política exterior: los casos de Argentina y Brasil". Estudios Internacionales, año 20, n80, (1987):442-490; Nohlen, Dieter y Fernández, Mario. "Democratización y política exterior. Análisis comparado en torno a tres casos: Argentina, Brasil y Uruguay. Estudios Internacionales. Año 24, n94,(1991): 229-259 ; Lasagna , Marcelo. "Cambio institucional y política exterior: un modelo explicativo" . Revista CIDOB d'afers internacionals, n³2,(1996): 45-64.

${ }^{71}$ Dentro de los actores políticos que apoyaron la campaña por el No en la Consulta Popular No vinculante, se destacan aquellos que formaban parte del Justicialismo que se encontraba dividido entre sus filas. Uno de sus máximos exponentes era Vicente Leónidas Saadi que, junto con al canciller Dante Caputo participaron en el primer debate público de la "transición democrática" en televisión. El debate fue transmitido por los canales 7 y 13 el jueves 15 de noviembre de 1984 (diez días antes de la elección) y si bien no podemos medir el impacto generado por el mismo, podemos afirmar que contribuyó al resultado final dentro de un clima emocional nacional que buscaba distanciarse del pasado inmediato de confrontación. En el debate, Saadi expuso sus argumentos a favor del No y entre ellos encontramos la utilización de los conceptos de "cercenamiento" o "desgarros" del espacio nacional, la incapacidad de los representantes de la política exterior argentina, una defensa del principio bioceánico (considerado que no se respeta con el Tratado), descalificaciones por realizar acuerdos con Pinochet, denuncia de traición a la patria, entre otras. Todas estas afirmaciones, lo ubican precisamente, dentro de la citada corriente.

${ }^{72}$ Etcheverry Boneo, Canal de Beagle..., p. 11.

Sobre18.350.863 electores hábiles, votaron 12.861.355, es decir un 70,09\%. Dentro de los votantes, 10.454 .172 se pronunciaron por el Sí (82,60\%), mientras que 2.201.963 lo hicieron por el No $(17,40 \%)$. Asimismo, hubo 141.121 votos en blanco $(1,10 \%)$ y 64.099 votos nulos $(0,50 \%)$. Datos extraídos de la Dirección Nacional Electoral. Consulta Popular, 25 de noviembre de 1984. Plebiscito Nacional No Vinculante - Tratado de Paz y Amistad firmado con Chile
} 
proclive a las concesiones, o más bien, a la pérdida de espacio territorial y marítimo, algo que para la corriente nacional territorialista irredentista era inaceptable. ${ }^{73}$ Del mismo modo, sostiene que el Tratado de Paz y Amistad (ratificado por las cámaras de senadores de ambas naciones en 1985), "lejos de constituir un freno para las políticas expansionistas, las ha fomentado".74 Dada su representación negativa sobre Chile y sus fundamentos de base irredentista, el arbitraje sobre Laguna del Desierto y sobre los Hielos Continentales ocurridos durante la década de 1990, serían evidencias de la continuidad en su política exterior, sobre todo en materia de fronteras. Pues en todas estas ocasiones, se habría cercenado el territorio nacional.

\section{A modo de conclusión}

A lo largo de este artículo hemos intentado exponer las diferentes posiciones en torno al conflicto Beagle entre Argentina y Chile entre 1977 y 1985. Particularmente, detuvimos nuestro análisis en las producciones intelectuales de dos funcionarios estatales, y militares de carrera, con participación dentro de este proceso que, hacia finales de 1978, se encaminaba hacia una guerra que parecía inevitable.

No obstante, la marcha atrás del Operativo Soberanía y de la inminente guerra vecinal, fue posible por una serie de factores que se conjugaron dar lugar a otros tipos de mecanismos de resolución. En base a nuestros análisis, consideramos que tanto los factores internos como los factores externos, favorecieron que el conflicto adquiera el camino hacia su resolución pacífica materializado en el Acta de Montevideo. El mismo distó de ser lineal y libre de obstáculos, puesto que una buena parte de las Fuerzas Armadas apostaba a la salida armada del conflicto, o al menos, a la invasión de las islas en disputa para poder negociar desde una posición de fuerza.

Dentro de este proceso, las producciones intelectuales de civiles y militares, pertenecientes a la corriente nacional territorialista irredentista, manifestaban su descontento con los términos en los cuales se llevaría a cabo la mediación y más aún, con las propuestas

\footnotetext{
${ }^{73}$ Dentro de las críticas esgrimidas por el general de brigada, podemos nombrar la "falta de dominio de los antecedentes históricos, una resistencia a la información sobre lo actuado durante seis años de negociaciones; una intención de "borrar el pasado", pretendiendo que se iniciaba una "nueva era"; sucesivos cambios en la dirección de la Misión, lo que provocó desorientación dentro de la Oficina de la Mediación; el descuido de temas fundamentales como la libertad de navegación por naves argentinas en toda el área del diferendo y el sobrevuelo de la misma, el trazado arbitrario de las línea de bases rectas por Chile, la neutralización de las islas, la importancia de obtener un límite con apoyos terrestres; el abandono arbitrario de la centenaria posición argentina sobre el Estrecho de Magallanes; un nuevo estilo de conducción austero y proclive a las concesiones, entre otros.

${ }^{74}$ Etcheverry Boneo, Canal de Beagle..., p.175.
} 
entregadas a ambos gobiernos. Actores tales como Osiris Villegas y Etcheverry Boneo dan cuenta acerca del desacuerdo existente en torno a las propuestas y esgrimieron que las mismas eran perjudiciales para la Argentina. Para justificar su posicionamiento, ambos recurrieron a la estrategia de desacreditación de Chile, posicionándolo como un país expansionista asociado a la potencia colonialista de Gran Bretaña. Bajo estas concepciones confrontativas, en donde la desconfianza es la base de los diferentes análisis realizados por estos militares argentinos, una alianza binacional tendiente a la integración plena no era una posibilidad real.

En el caso de Etcheverry Boneo, las negociaciones entabladas durante su gestión estuvieron por momentos paralizadas, ya que cualquier propuesta de solución que incluyera una "cesión" territorial por parte de la Argentina era de por sí inviable. No obstante, la sola presencia de este militar de carrera dentro de las comisiones negociadores argentinas, no alcanzaría para fundamentar esta hipótesis, aunque sí nos permite inducir que existía una correlación con una de las perspectivas presentes dentro del gobierno dictatorial heterogéneo. $\mathrm{Al}$ respecto, dejamos planteado para futuras investigaciones que los márgenes de autonomía de los representantes argentinos en el proceso de mediación, se estrecharon en el momento en que asume al poder el gobierno democrático de Raúl Alfonsín. Entretanto, el general Osiris Villegas, figura con gran prestigio dentro del Ejército y de importante participación en las misiones diplomáticas durante el año 1977, procuró generar consensos por fuera del aparato estatal a partir de sus producciones intelectuales. Publicando numerosos artículos y obras impresas, continuó realizando contribuciones tendientes a influenciar sobre el proceso de toma de decisiones de Estado en materia de política exterior, empero, sin demasiado éxito.

Parte de la explicación de esta situación, se halla en las características propias del clima emocional nacional argentino de la posguerra de Malvinas que habría afectado a la manera en las que las producciones intelectuales de la corriente nacional territorialista irredentista entendían el conflicto Beagle, sobre todo en base a concepciones geopolíticas confrontativas. Dicho de otra manera, el irredentismo no desapareció, aunque pasó a estar en un segundo plano dentro de los trabajos abocados a estas problemáticas. En el marco de estas apreciaciones, consideramos que el Tratado de Paz y Amistad entre Argentina y Chile (1985) marcaría el inicio del proceso de conformación de una comunidad de seguridad naciente, en donde las concepciones geopolíticas confrontativas no encontrarían mayor difusión. 